NIST

PUBLICATIONS

\title{
COMPARISON OF WALL-FIRE BEHAVIOR WITH AND WITHOUT A CEILING
}

Henri E. Mitler and Kenneth D. Steckler

Building and Fire Research Laboratory

Gaithersburg, Maryland 20899

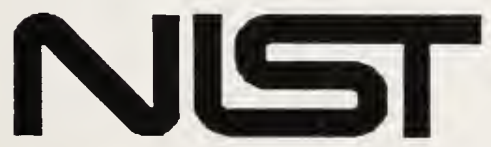

$$
\begin{array}{ll}
\text { QC } & \text { tes Department of Commerce } \\
100 & \text { y Administration } \\
.456 & \text { stitute of Standards and Technology } \\
\text { No.5380 } & \\
1993 &
\end{array}
$$





\section{COMPARISON OF WALL-FIRE BEHAVIOR WITH AND WITHOUT A CEILING}

Henri E. Mitler and Kenneth D. Steckler

November 1993

Building and Fire Research Laboratory

National Institute of Standards and Technology

Gaithersburg, MD 20899

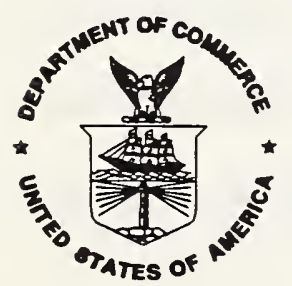

\section{U.S. Department of Commerce}

Ronald H. Brown, Secretary

Technology Administration

Mary L. Good, Under Secretary for Technology

National Institute of Standards and Technology

Arati Prabhakar, Director 



\section{TABLE OF CONTENTS}

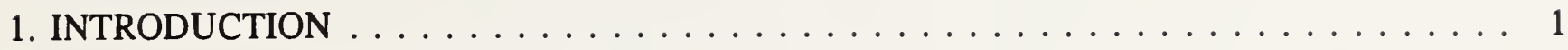

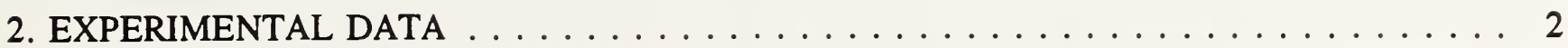

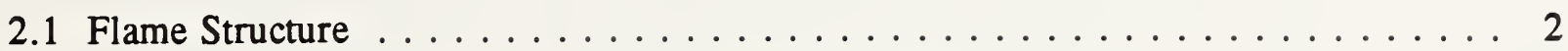

2.2 Fires Beneath an Inert Ceiling $\ldots \ldots \ldots \ldots \ldots \ldots \ldots \ldots \ldots \ldots$

2.2.1 Effects of inert ceiling on pyrolysis rate of fixed area fire ......... 3

2.2.1.1 FMRC PMMA pool fire experiment $\ldots \ldots \ldots \ldots \ldots \ldots$

2.2.1.2 British work $\ldots \ldots \ldots \ldots \ldots \ldots \ldots \ldots \ldots \ldots$

2.2.1.3 FMRC wall/ceiling-channel experiments . . . . . . . . 4

2.2.1.4 NIST reduced-scale wall-fire experiments $\ldots \ldots \ldots \ldots \ldots$

2.2.2 Effects of inert ceiling on spread rate of fire $\ldots \ldots \ldots \ldots \ldots$

2.3 Fires Beneath a Combustible Ceiling $\ldots \ldots \ldots \ldots \ldots \ldots \ldots$

2.3.1 Effects of flammable ceiling on pyrolysis rate of fixed area fires $\ldots \ldots \ldots 7$

2.3.2 Effects of flammable ceiling on spread rate of fire $\ldots \ldots \ldots \ldots$

2.4 Other effects $\ldots \ldots \ldots \ldots \ldots \ldots \ldots \ldots \ldots \ldots \ldots \ldots$

3. MODEL PREDICTIONS $\ldots \ldots \ldots \ldots \ldots \ldots \ldots \ldots \ldots \ldots$

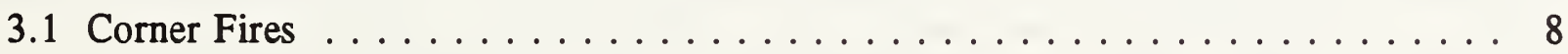

3.2 Flat-wall fires $\ldots \ldots \ldots \ldots \ldots \ldots \ldots \ldots \ldots \ldots \ldots \ldots$

4. CONCLUSIONS AND DISCUSSION $\ldots \ldots \ldots \ldots \ldots \ldots \ldots \ldots \ldots \ldots$

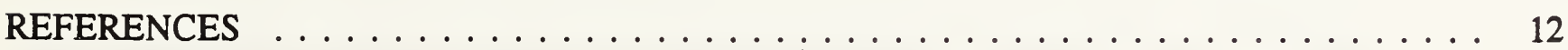

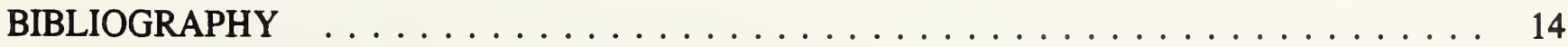

FIGURE CAPTIONS . . . . . . . . . . . . . . . . . . . . . . . . . 17 

COMPARISON OF WALL-FIRE BEHAVIOR WITH AND WITHOUT A CEILING

\author{
H.E. Mitler and K.D. Steckler \\ Building and Fire Research Laboratory \\ October, 1993
}

\begin{abstract}
This paper demonstrates that the effects of the ceiling on the progress of a wall fire are quite significant, and that a project to quantify and model the effects of a ceiling on the progress of a wall fire is indeed needed. Experimental results from the open literature, as well as previously-unpublished experimental results obtained at NIST, are used. The wall-fire model SPREAD and the room-fire model FIRST are used seriatim to show that some of these effects can now be calculated.
\end{abstract}

Key words: ceiling fires, fire research, radiation feedback, spread rates, wall fires.

\title{
1. INTRODUCTION
}

The objective of this work is to develop an understanding of the effects of a ceiling on the evolution of a wall fire, and on the subsequent spread of the fire across the ceiling. The intent is to produce an algorithm suitable for inclusion into computer fire models, particularly HAZARD (Peacock and Bukowski 1990; Peacock et al 1991). We initially focus on fires on flat walls (rather than corner fires), in rooms with unobstructed ceilings. 
A number of wall-fire models exist (see, for example, Mitler and Steckler 1993), but they do not consider the presence of a ceiling. On the other hand, as we shall show, the presence of a ceiling will at times strongly affect how a wall fire burns and spreads, especially in the late stages of the fire.

This report reviews published information and presents heretofore unpublished data that demonstrate the effects and significance of the presence of a ceiling on fire growth. It also identifies areas where additional information is needed to develop algorithms which predict these fire behaviors. There is, surprisingly, relatively little data directly bearing on the effects of ceilings on fire spread. We have collected as much as is readily available in English, and discuss it in the next section.

\section{EXPERIMENTAL DATA}

\subsection{Flame Structure}

Williamson et al (1984) looked at full-scale corner-fire flame morphologies and concluded that some important features are rooted in turbulence conditions. They observed that as flames extended to (or spread up to) a ceiling from a corner fire, a characteristic "T" pattern was produced by arms, or extensions, running along the intersection of the wall(s) and ceiling. These horizontal flame extensions were observed to have a distinct spiral structure. Williamson suggested that these spiral horizontal extensions are due to vortices formed at the intersection of the walls and ceilings.

This was observed when the linings were combustible as well as during calibration experiments with inert linings. They believe these vortex structures are formed on one wall and then captured by the flow on the other wall (the other arm of the "T") and swept across the ceiling. Other cited possibilities are that the detached vortices

"are a result of either or both of the following mechanisms: vortex-line-turning at the wall-ceiling junctures due to spatial variations in the flow field, or the boundary layer breakdown away from the junction, and the resulting formation of streamwise vortices".

Williamson hypothesized that these detached vortex flame structures may be a significant mechanism for flame exposure to the central area of the ceiling.

Since the "T" pattern occurred for inert as well as for flammable ceilings, this implies that it is a fluid-mechanical (in contrast to combustion) aspect of the phenomenon. Satoh (1989) performed 3-dimensional numerical fluid-dynamic calculations to predict the thermal convection of ceiling jets in geometries similar to the calibration experiments. In these calculations, the gas flow was driven by a volumetric heat source located in or near the corner and near the floor. The results in terms of isotherms, isobars, and velocity vectors all exhibited the characteristic " $T$ " pattern when there was a substantial gap between the corner heat source and the wall. 
When the gap was small or non-existent, the " $\mathrm{T}$ " pattern disappeared and was replaced by a circular ceiling jet.

The "T" pattern also occurs during fire growth on a flat wall. Quintiere (1989) shows this pattern in photographs of a full-scale room-fire test in which a line-burner on the floor ignited the central section of a PMMA-lined wall beneath a non-combustible ceiling.

The extensions are a major factor in rapidly spreading the fire to large areas of combustible wall linings near the ceiling. Indeed, these wall areas can supply enough energy to the upper layer so that flashover can occur without additional flamespread on the ceiling or lower sections of the walls. For this reason, it is important to account for the " $T$ " pattern phenomenon in roomfire models. As mentioned above, this has been done theoretically for corner fires; it must also be done for flat-wall fires.

\subsection{Fires Beneath an Inert Ceiling}

We first outline some of the physics involved when flames impinge on the ceiling. Briefly, the effects are as follows: In a 1969 paper on the effects of flammable linings on fire spread, Thomas (1969) pointed out that the role of a ceiling in fire spread is threefold: 1) it deflects the flame and hot gas in directions that usually enhance the energy feedback to the burning object and to other combustibles, 2) its thermal insulation can cause higher upper-layer gas and ceiling surface temperatures and attendant thermal radiation to other combustibles sooner, and 3) its own combustibility spreads the fire. Thomas used the work of Hinkley et al $(1968,1969)$-apparently the most relevant and comprehensive studies available in 1969 -- to quantify these effects.* Since then, a few other studies have produced data that to some extent demonstrate the effect of the ceiling on fire growth and/or provide information needed to model the ceiling fire.

2.2.1 Effects of inert ceiling on pyrolysis rate of fixed area fire

\subsubsection{FMRC PMMA pool fire experiment}

Friedman (1975) reported on an experiment carried out at FMRC by R. Alpert. They compared mass-loss rate results of a PMMA slab (0.76 m square) burning in the open with those of an identical slab burning in a steel enclosure, $0.61 \mathrm{~m} \times 0.91 \mathrm{~m} \times 0.61 \mathrm{~m}$ high, with the end "walls" missing. Flames were observed to emerge from the open ends during the enclosure test. The maximum burning rate for PMMA in the enclosure was three times that measured in the open burn. This was presumed to be due to increased radiative feedback due to flame deflection by the ceiling, heating of the ceiling, and the possible formation of a shallow hot gas layer within the enclosure.

* Even though their work was published in 1984, the unpublished reports on which it was based appeared in 1968 and 1969. 


\subsubsection{British work}

Hinkley et al (1984) considered flames spreading under a corridor ceiling. They showed that the ceiling flames' radiation to various targets in the room, such as the floor and the walls, is considerably greater than from the vertical flames on the wall, even for non-combustible ceilings. The effects can be sufficient to produce flashover in an enclosure, where there would be none if there were no ceiling yet the walls were high enough to produce the same length of vertical flame.

\subsubsection{FMRC wall/ceiling-channel experiments}

Alpert et al (1981) conducted a series of experiments designed to study fire growth along the ceiling of an aircraft fuselage. The long ceiling channel formed by the aircraft's ceiling and walls was simulated with a $2.4 \mathrm{~m} \times 0.46 \mathrm{~m} \times 0.23 \mathrm{~m}$ (deep) test channel. The geometry is essentially the same as for the British work. The side walls of the test channel were made of inert ceramic board, while the replaceable ceiling was either ceramic board or aircraft material. At one end of the channel was a wall consisting of a $0.305 \mathrm{~m} \times 0.9 \mathrm{~m}$ high PMMA panel separated from the ceiling by a $0.32 \mathrm{~m}$ high ceramic-board panel. The other end was open. At the start of each experiment, the PMMA panel was ignited near its base, producing flames that eventually extended into the ceiling channel. Vertical side walls attached to the edges of the PMMA/inert wall insured that all of the fire effluent was directed into the channel. These side walls were inert and $76 \mathrm{~mm}$ deep. They also served to make the experiments approximately two-dimensional (that is, independent of the y coordinate, defined by the intersection of the wall and ceiling). Figures 1 and 2 from that report, showing the experimental arrangement, are reproduced here (with the permission of FMRC).

Time-averaged mass-loss rates per unit area along the vertical centerline $0.23 \mathrm{~m}$ and $0.69 \mathrm{~m}$ above the base of the PMMA panel were determined for an experiment in which an inert ceiling was in place. These rates were $23 \%$ and $44 \%$ higher, respectively, than rates measured at the same elevations on a PMMA panel burning in the open.

Alpert et al (1981) checked the consistency of these mass-loss-rate enhancements with the attendant measured steady-state temperatures and depths of the hot-gas layer in the channel using a model for radiant heat flux from a ceiling layer with temperatures and absorption coefficients which are nonuniform in any of the three dimensions. The calculated enhancements in mass-loss rates at the $0.23 \mathrm{~m}$ and $0.69 \mathrm{~m}$ elevations were $31 \%$ and $62 \%$, respectively, somewhat higher than the $23 \%$ and $44 \%$ found experimentally. The difference is attributed to the fact that the experimental values represent time-averages over the entire fire-growth period rather than at steady-state conditions.

Although they did not make comparison measurements (ceiling versus no ceiling) for the fluxes or their effects on the floor, the increased flux which was calculated to have been received by the wall is qualitatively consistent with both a greater rate of heat release from the wall, and a higher upward spread rate. 
In this subsection, we report on heretofore unpublished work done at NIST. Three experiments from a series reported in part by Steckler and Mitler (1988) show the effect of a non-combustible ceiling on the pyrolysis rate of a fully-ignited PMMA wall segment in a reduced-scale compartment. Since the series was designed to study the pyrolysis process, heat fluxes at locations near the burning wall were measured, but flame patterns on the ceiling were not. Moreover, although video recordings are available, the viewing angle precludes meaningful measure of the flame extension beneath the ceiling. Consequently, these experiments demonstrate the quantitative effect of a ceiling on the burning rate of a fully-ignited wall panel, but are deficient in information needed to model the flame extension beneath the ceiling.

The experimental arrangement is shown in Fig. 3. The dimensions of the PMMA panel were $0.18 \times 0.72 \times 0.025 \mathrm{~m}$. The remaining surfaces of the compartment were non-combustible $0.019 \mathrm{~m}$ calcium silicate board.

A natural-gas line burner located at the base of the PMMA panel was used to ignite the surface of the panel. Operating at a steady $6 \mathrm{~kW}$, the burner produced a flame sheet that covered approximately 60 percent of the height of the panel. The burner was operated at this level for 450 seconds, and was then turned off. In most experiments, the entire surface of the panel was burning within this period. The experiment proceeded until the softened sample curled away from the steel support to which it was bolted, and (eventually) fell to the floor.

Measurements included the mass of the PMMA panel, radiant flux to ellipsoidal radiometers mounted flush on the rear wall at two levels, and total heat flux to a Gardon gauge mounted flush at the center of the floor.

The relevant test configurations were:
\#1 -..-- open front with soffit (Fig. 3).
\#2 ----- open front without soffit.
\#3 ----- open front without soffit and without ceiling.

Configuration \#3 is equivalent to a "free burn"** (no ceiling effect), \#2 represents a ceiling jet (flame and hot gases) without an additional (relatively quiescent) ceiling hot gas layer, and \#1 represents a ceiling jet within a hot gas layer.

Mass-loss rates for the three configurations are presented in Fig. 4. These rates are the slopes of a "running" 9-point linear least-squares fit to the mass-versus-time data recorded during the

\footnotetext{
** A free-burn experiment conducted with only the compartment's floor and back wall in place produced results within the experimental error of those found for configuration \#3. The latter results were chosen for the current comparisons because the sample remained in its holder approximately 120 seconds longer than during the free-burn experiment.
} 
experiments. Further smoothing using a 20-point running average yielded Fig. 5 which clearly shows the effects of the ceiling jet and hot gas layer***.

The effects of the ceiling jet and layer on radiative heat fluxes at two levels on the back wall are shown in Figs. 6 and 7. Total heat fluxes measured at the center of the floor are presented in Fig. 8. Note that in the latter figure a level of $20 \mathrm{~kW} / \mathrm{m}^{2}$--- a level sometimes associated with flashover (Waterman 1968) --- was achieved at the center of the floor when the ceiling jet/layer was allowed to form.

The experimental mass-loss rates and radiative fluxes to the rear wall afford an opportunity to assess the consistency of these data. If at a given time the average of the fluxes at the two levels on the rear wall is taken as representative of the average external radiative flux absorbed over the surface of the PMMA panel, the effect of radiation enhancement on mass-loss rate can be estimated using the equation

$$
\dot{\mathrm{m}}^{\prime \prime}(\mathrm{t})=0.5\left[\Delta \mathrm{q}_{\mathrm{u}}{ }^{\prime}(\mathrm{t})+\Delta \mathrm{q}_{\mathrm{l}}{ }^{\prime}(\mathrm{t})\right] \mathrm{A}_{\mathrm{s}} / \mathrm{L}_{\mathrm{v}}+\dot{\mathrm{m}}_{\mathrm{fb}}{ }^{\prime \prime}(\mathrm{t})
$$

where

$\dot{m} "(t) \quad$ is the mass-loss rate of the burning PMMA panel in the presence of external radiation,

$\Delta q_{u}{ }^{\prime \prime}(t)$ is the difference between the radiant fluxes measured at the upper level during the free-burn and ceiling-jet/layer experiments,

$\Delta \mathrm{q}_{1}{ }^{\prime \prime}(\mathrm{t})$ is the difference between the radiant fluxes measured at the lower level during the free-burn and ceiling-jet/layer experiments,

$\mathrm{A}_{\mathbf{s}} \quad$ is the area of the sample,

$\mathrm{L}_{\mathrm{v}}$ is the effective heat of vaporization of PMMA, $1.62 \mathrm{~kJ} / \mathrm{kg}$ (Tewarson and Pion 1976), and

$\dot{\mathrm{m}}_{\mathrm{fb}}{ }^{\prime \prime}(\mathrm{t}) \quad$ is the mass-loss rate during the free burn (configuration \#3).

These calculations were made and the results are compared with the experimental results in Fig. 9. As can be seen, the calculated values appear to match the experimental values very well. For most points, the calculated points lie on or very near the appropriate curves; the points at $t=1080 \mathrm{~s}$ and $\mathrm{t}=1200 \mathrm{~s}$ deviate somewhat, but we must take two facts into account: first, there are random errors made in the radiation flux measurements used in equation (1). Second, and more important, we note that even after considerable smoothing, the experimental curves still display substantial fluctuations; in particular, one can observe a substantial dip in the base curve (curve \#3) at $\mathrm{t}=1080 \mathrm{~s}$. Therefore the calculated values are pulled down by the same magnitude as the dip; that accounts for most of the difference, for the circle as well as for the triangle. Since collapse of the PMMA samples ended each test before burnthrough occurred, it is not known whether the relative effects of the jet and jet/layer might have changed at times beyond that point, although it is highly unlikely that they would.

\footnotetext{
*** As a point of reference, during the reduced-scale compartment experiments a maximum mass loss-rate of about $5 \mathrm{~g} / \mathrm{s}$ was measured at approximately 1400 seconds when the width of the opening, $W_{o}$ (Fig. 3), was in the range 0.18 to $0.33 \mathrm{~m}$ (Steckler and Mitler 1988).
} 
These experiments with a fully-ignited slab showed that the presence of a ceiling made a large difference in the burning rate of the "wall" (that is, the PMMA sample mounted on the wall).

\subsubsection{Effects of inert ceiling on spread rate of fire}

Alpert et al (1981) reported an increase in the growth rate of a PMMA wall fire due to the presence of an inert ceiling. The experimental arrangement was the wall/ceiling channel described above. The exponential growth factor, which is the ratio of the speed of the pyrolysis front, $\mathrm{dx}_{\mathrm{p}} / \mathrm{dt}$, to its coordinate, $\mathrm{x}_{\mathrm{p}}$, increased from $0.0024 \mathrm{~s}^{-1}$ during the free burn to $0.0027 \mathrm{~s}^{-1}$ beneath the inert ceiling.

\subsection{Fires Beneath a Combustible Ceiling}

\subsubsection{Effects of flammable ceiling on pyrolysis rate of fixed area fires}

Hinkley et al (1984) carried out experiments with combustible ceilings as well as with inert ones. As might be expected, all the effects which occurred with inert ceilings also occurred with combustible ones, and were, indeed, enhanced. That is, the longer ceiling flames which resulted, increased the view factors to the pyrolyzing wall and to the floor, resulting in a further increase of the pyrolysis rate of the fixed area wall fire, beyond what the inert ceilings provided.

\subsubsection{Effects of flammable ceiling on spread rate of fire}

The ceiling flames obtained by Hinkley et al with inert ceilings sometimes produced a sufficiently intense heating flux at the floor that when the floor was flammable (wood), it would ignite the floor, and that new fire would spread along the floor. When the ceiling was combustible, the ceiling flames were longer and resulted in an accelerated spread rate for the floor fire. There was no discussion of spread rate on the wall.

Mao and Fernandez-Pello (1988) performed a series of wall-ceiling channel experiments in an apparatus similar to those discussed above, but at a smaller scale. One end of the $152 \mathrm{~mm}$ wide channel was open and the other end was closed by a vertical wall. The side walls were made of pyrex glass, and there was no floor. The ceiling and end wall were lined with $12.7 \mathrm{~mm}$ thick PMMA. The end wall was ignited at its base and the spread rate up the wall and across the ceiling was recorded.

Experiments were carried out with end walls having heights ranging from $76 \mathrm{~mm}$ to $356 \mathrm{~mm}$ and ceiling lengths in the same range. Mao observed that for a PMMA lining the spread rate across the ceiling was affected considerably by the height of the wall, but the upward spread rate on the wall was "practically independent of the ceiling length." In view of the $12.5 \%$ increase in the growth-rate factor measured by Alpert (sec. 2.1.2), the smaller-scale work of Mao 
suggests that scale is an important factor in wall-ceiling interactions. This is to be expected, since it is known that radiation scales nonlinearly, with apparatus size.

\subsection{Other effects}

The effects of a ceiling, on the other hand, are not always so intuitively clear. Thus, Saito (1993) has made measurements of the flame fluxes to the wall and of the resulting wall temperatures in a corner, as a function of time, for corner fires with and without ceilings. As expected, in the upper region of the corner the measured fluxes and temperatures were greater when the ceiling was present. Contrary to expectation, however, the heating fluxes and resulting wall temperatures in the lower region of the corner were reduced by the introduction of a ceiling; see figures 10 and 11 (reproduced here with the permission of Prof. Saito). The tentative interpretation of this latter result is that the pressure increase due to the presence of the ceiling lowers the flow velocity in the corner, which produces a decrease of the convective heating flux which outweighs any increase in radiative flux from the ceiling region to the lowercorner region.

\section{MODEL PREDICTIONS}

\subsection{Corner Fires}

Cleary and Quintiere (1991) developed an analytical model which utilizes fire-test data from available test methods such as the cone calorimeter (Babrauskas 1984; ASTM) and LIFT (Quintiere and Harkleroad, 1985) apparatuses to estimate fire spread over combustible walls, ceilings, and floors. Ceiling fire spread is treated as a simple extension of upward wall fire spread; that is, wind-aided wall spread theory is applied also to the combustible ceiling. The assumed scenario is that the fire starts at the base of a wall corner, grows upward by wind-aided flame spread and laterally by opposed-flow flame spread. When the pyrolysis front reaches the ceiling, the (assumed flammable) ceiling ignites and wind-aided lateral fire spread begins along the wall-ceiling interface. The ceiling spread follows the wall-ceiling-interface spread to form a ceiling pyrolysis area which is the quadrant of a circle with a radius equal to the distance from the corner to the wall-ceiling interface pyrolysis front.

The model is exercised with external flux and wall surface temperature as adjustable parameters. These parameters, which are chosen a priori, are a very approximate means for taking into account the interactions between the wall fires, ceiling fires, and the enclosure's bounding surfaces and gas layers.

Quintiere (1993) has improved this model by coupling it to a room-fire model which accounts for time-dependent interactions between the enclosure and the heat release and flame spread processes. Radiative feedback from the hot gas layer is used to compute surface temperatures in front of the pyrolysis fronts. These temperatures control the spread rates. The radiative feedback also constitutes the external flux which is used to calculate the heat release rate from 
the pyrolysis area. This version of the model provides for downward (opposed-flow) spread from the wall-ceiling interface, which is driven by heat transfer from the hot gas layer.

Thomas and Karlsson (1991) analyzed experimental data found in the literature to estimate flame extension along the wall-ceiling intersection due to a corner fire. They found a linear correlation between the rate of heat release and the flame length along the wall-ceiling intersection. Karlsson (1992) uses this correlation in his analytical "Model B" for a corner fire in a room with combustible walls but an noncombustible ceiling. The heat release rate from the wall material is based on cone calorimeter data. Specifically, the heat release rate per unit area is idealized as an instantaneous jump (from zero) to the maximum rate measured in the cone calorimeter, which then decays exponentially. The wall-ceiling interface spread sub-model in Model B is based on concurrent-flow flame spread theory. It assumes that the height (or "width", if that is preferred) of the "arms" of the corner "T pattern" are fixed at $7.5 \%$ of the height of the room until the horizontal spread in the arms stops or reaches an opposite corner. Then downward wall-fire spread ensues in accordance with opposed-flow flame spread theory, driven by the heating of the wall by the hot gas layer. This is a reasonable model, though the (constant) $7.5 \%$ assumption may be simplistic.

Karlsson (1992) also treats the case in which the walls and ceiling are combustible (his "Model $\mathrm{A}^{\prime \prime)}$. He uses the work of Andersson and Giacomelly (1985) to model flame area over a combustible ceiling as a linear function of heat release rate. Spread on the ceiling is based on concurrent-flow flame spread theory. Downward wall-fire spread is not treated in this model.

\subsection{Flat-wall fires}

SPREAD (Mitler and Steckler 1993) is the explicit implementation of a model which has been developed for predicting the ignition of, and the subsequent rate and extent of fire spread on, vertical surfaces (generally, flat walls) in a room using the fire properties of the materials involved. The principal mode of spread is upward. The presence of a ceiling, however, will materially affect how a wall fire burns and spreads, especially in the late stages. These effects have not yet been taken into account, except in the following limited way:

The calculations also include the lateral (creeping) spread on the wall. For the latter calculations, the fact that the room produces a two-layer environment has been taken into account (the lateral spread rate within the upper layer is greater than in the lower one). This is only done in a limited way, however: the "external" fluxes (from the hot gas layer and hot ceiling) must be specified a priori by the user. This is also true of the upper wall temperatures outside of the preheating and pyrolyzing region.

Embedded in the overall model is a general pyrolysis submodel, specially developed for this purpose, which treats arbitrary materials (ablating, char-forming, composite, etc.). SPREAD also calculates the regression of the pyrolyzing surface, including the possible burnout of the wall/slab at any point. 
As noted for the case of corner fires, a successful flat-wall flame spread model must take into account the effects of a hot upper gas layer in a compartment as well as the effects of flame splashing on a ceiling and spreading. One would need to generalize a method such as developed by Quintiere for the corner fire case, or generalize SPREAD to include the ceiling effects.

One can simulate a partial solution to this problem by coupling the output of a room-fire model such as FIRST (Mitler and Rockett, 1987), with a flat-wall unconfined-flame spread model such as SPREAD. This provides an estimate of the effect of a hot upper gas layer in a compartment on the rate of heat release and spread rate of a burning flat wall. However, this still leaves us without an estimate of the effect of flame splashing against the ceiling.

As an example of such a procedure, SPREAD and FIRST were used to estimate the impact of a ceiling on the rate of heat release of a vertical slab of PMMA, of dimensions $0.61 \mathrm{~m} \times 2.44 \mathrm{~m}$ (2' $\left.x 8^{\prime}\right)$. Initially, SPREAD was used to estimate the rate of heat release as a function of time, for an unconfined slab of those dimensions, assuming no external radiation. This information was used as input data for FIRST. FIRST then calculated the radiation fluxes to the walls from the hot layer, ceiling, and other walls.

Then SPREAD was run again, this time with these calculated fluxes $\phi(t)$ from the surrounding environment as external flux input data to SPREAD, to obtain the resulting new spread rate and rate of heat release.

The results of such a set of calculations for a slab of PMMA are shown in figure 12. From curve NC, we see that in the open the slab ignites at $t=198 \mathrm{~s}$, and the RHR goes up to about $355 \mathrm{~kW}$ when the pyrolysis front reaches the top of the slab (at $t \approx 700 \mathrm{~s}$, as indicated by the arrow at the top of the figure). The slight subsequent increase in the power output is due to heating up of the slab itself, resulting in a slow decrease in the heat of gasification. Curve $\mathrm{C}$ shows that when the slab is exposed to the extra fluxes from the hot layer and ceiling, it ignites 20 seconds earlier. The pyrolysis front reaches the top almost three minutes sooner (again indicated with an arrow), with a power output of about $390 \mathrm{~kW}$.

Even with such a crude procedure, it can be seen that the extra fluxes have a substantial acceleratory effect.

\section{CONCLUSIONS AND DISCUSSSION}

A ceiling can have a significant effect on wall-fire behavior. The magnitude of the effect varies depending on the enclosure, geometry, igniting fire, etc.; it is directly related to the heating enhancements caused by confining the flame and gases within the compartment. The geometric effect relates to the ratio of the ceiling height to open-flame height. The width of the fire influences the flame height (for a given power output) and magnitude of end losses. Whether the fire is in a corner, against a flat wall, or somewhat removed from the walls, has a strong effect on flame heights and extensions and therefore spread rates, and may be differently 
influenced by the presence of the ceiling. The size and location of the vent(s) for the room also strongly influence the hot layer depth and therefore the feedback to the fire.

In light of this, it would be interesting to generalize SPREAD so as to take account of the ceiling. All of this is to be seen within the context that we are incorporating pyrolysis and flame spread into the current version of the fire growth and smoke transport model (CFAST) which is used to model building fires. The first extension of CFAST will be to include SPREAD, the simple model described above, which does not yet fully and dynamically account for the ceiling effects.

The proposed work will be novel in two ways:

a. First, it will be the first time that the effect of the ceiling in an enclosure will have been calculated for a fire against a flat wall.

b. Second, it will be the first time that the feedback effect of the splashing flames has been calculated.

Referring to item $b$, even when the effect of the ceiling has been taken into consideration, as in the work by Quintiere and by Thomas and Karlsson, it has only been the effect of the hot layer which has been estimated, as done here in Section 3.

As stated in the Introduction, the data currently available from the literature are insufficient for constructing an accurate algorithm describing the behavior of a wall fire once the flames "splash" against the ceiling, and then checking it. Some of the information that is needed is

a. The flow(s) of the thermal plume upon impact on the ceiling.

b. The resulting morphology of the flames.

c. Quantitative description of the length, width, and thickness of the arms (flame extensions) which form at the wall/ceiling intersections. Also, their dependence on various parameters, such as the strength of the fire, the height of the ceiling, the width of the wall flame, etc.

d. A similar description for the part of the flame which may extend under (or along) the ceiling.

e. The heating fluxes back to the wall and ceiling, from the several flame extensions (again as a function of the various parameters).

f. The spread rates of the extensions. 


\section{REFERENCES}

Alpert, R.L., Mathews, M.K., and Modak, A.T. (1981) "Modeling of Ceiling Fire Spread and Thermal Radiation," Report No. DOT/FAA/CT-81/70, U.S. Department of Transportation, Federal Aviation Administration, Washington, DC, October 1981.

Alpert, R.L., Mathews, M.K., and Modak, A.T. (1981) "Modeling of Ceiling Fire Spread and Thermal Radiation," FMRC Technical Report J.I. OE0N8.BU, Factory Mutual Research Corp., Norwood, Mass.

Andersson, C., and Giacomelli, C. (1985) "Ett Modellrum i Lagor," Dept. of Fire Safety Eng., Lund University, Lund, Sweden.

ASTM; "Standard Test Method for Heat and Visible Smoke Release Rates for Materials and Products Using an Oxygen Consumption Calorimeter," ASTM E1354, Amer. Soc. for Testing and Materials, Philadelphia, PA

Babrauskas, V. (1984) "Development of the Cone Calorimeter -- a bench-scale heat release rate apparatus based on oxygen consumption," Fire and Materials 8, No.2, p.81

Cleary, T.G., and Quintiere, J.G. (1991) "A Framework for Utilizing Fire Property Tests," in Fire Safety Science - Proceedings of the Third Int'l Symposium (Eds., G. Cox and B. Langford), Elsevier Applied Science, N.Y., p. 647

Drysdale, D. (1985) An Introduction to Fire Dynamics, John Wiley \& Sons

Friedman, R. (1975) "Behavior of Fires in Compartments," International Symposium on Fire Safety of Combustible Materials, University of Edinburgh, Centre for Industrial Consultancy and Liaison, October 1975, pp. 100-113.

Hinkley, P.L., Wraight, H.G.H., and Theobold, C.R., (1968) "The Contribution of Flames Under Ceilings to Fire Spread in Compartments Part I. Incombustible Ceilings," Joint Fire Research Organization Fire Research Note No. 712, Fire Research Station, Borehamwood, England.

Hinkley, P.L., Wraight, H.G.H. (1969) "The Contribution of Flames Under Ceilings to Fire Spread in Compartments Part II. Combustible Ceiling Linings," Joint Fire Research Organization Fire Research Note No. 743, Borehamwood, England.

Hinkley, P.L., Wraight, H.G.H., and Theobold, C.R., (1984) "The Contribution of Flames Under Ceilings to Fire Spread in Compartments," Fire Safety J. 7, No.3, p.227

Karlsson, B. (1992) "Modeling Fire Growth on Combustible Lining Materials in Enclosures," Report TVBB-1009, Dept. of Fire Safety Engineering, Lund University, Lund, Sweden (thesis) 
Mao, C-P., and Fernandez-Pello, C.P. (1985) "Flame Spread Over a Wall-Ceiling Corner," paper 56 in the Proceedings of the Fall Technical Meeting of the Eastern Section of the Combustion Institute: Chemical and Physical Processes in Combustion; the Combustion Institute, Pittsburgh, PA

Mitler, H.E., and Rockett, J.A. (1987) "Users' Guide to FIRST, a Comprehensive Single-Room Fire Model", NBSIR 87-3595; National Bureau of Standards, Gaithersburg, MD.

Mitler, H.E., and Steckler, K.D. (1993) "Documentation of the BFRL Wall-Fire Spread Program," NISTIR, in review.

Peacock, R.D., and Bukowski, R.W. (1990) "A Prototype Methodology for Fire Hazard Analysis," Fire Technology, 26: 1, pp. 15-40.

Peacock, R.D., Jones, W.W., Bukowski, R.W., and Forney, C.L. (1991) "Technical Reference Guide for the HAZARD I Fire Hazard Assessment Method," NIST Handbook 146, Vols 1 and 2, National Institute of Standards and Technology, Gaithersburg, MD 20899

Quintiere, J.G., and Harkleroad, M.F. (1985) "New Concepts for Measuring Flame Spread Properties," NBSIR 84-2943, National Bureau of Standards, Gaithersburg, MD 20899, 1984. Also published as Fire Safety Science and Engineering (ASTM STP 882), T.Z. Harmathy, ed., American Society for Testing and Materials (ASTM), Philadelphia, PA, pp.239-267

Quintiere, J.G. (1989) "State of Fire Research and Safety", in Fire Safety Science, Proceedings of the Second Int'l Symposium (Eds., T. Wakamatsu, Y. Hasemi, A. Sekizawa, P. Seeger, P. Pagni, and C. Grant), Hemisphere Publishing Corp., N.Y., pp. 15-28.

Quintiere, J.G. (1993) "A Simulation Model for Fire Growth on Materials Subject to a RoomCorner Test," Fire Safety Journal 20, p.313

Saito, K. (1993) Grant progress report; to be published.

Satoh, K. (1989) "A Numerical Study of Ceiling Jets Based on "T" Pattern Flames," in Fire Safety Science - Proceedings of the Second International Symposium (Eds., C.E. Grant and P.J. Pagni); Hemisphere Publishing Corp., p.159.

Steckler, K.D., and Mitler, H.E. (1988) "Experimental Study of the Pyrolysis Rate of a PMMA Wall Panel in a Reduced-Scale Enclosure," Combustion Institute/Eastern Section; Chemical and Physical Processes in Combustion; Technical Meeting, Clearwater Beach, FL, pp. 73/1-4, Dec. 1988.

Tewarson, A., and Pion, R.F. (1978) "Flammability of Plastics. I. Burning Intensity," Combustion and Flame, 26, p. 85-103.

Thomas, P.H. (1969) "The Role of Flammable Linings in Fire Spread," Board Manufacture, Pressmedia Ltd., September 1969. 
Thomas, P.H., and Karlsson, B. (1991) "On the Length of Flames Under Ceilings," J. of Fire Sciences 9, Nov/Dec, p.527

Waterman, T.E. (1968) "Room Flashover -- Criteria and Synthesis," Fire Technology 4, p.25-31

Williamson, R.B., Mowrer, F.W., and Fisher, F.L. (1984) "Observations of Large Scale Turbulence in Corner-Wall Experiments," Combustion Science and Technology, 41, pp. 83-89.

\section{BIBLIOGRAPHY}

Axisymmetric fires:

Alpert, R.L. (1971) "Fire-Induced Turbulent Ceiling Jet," FMRC Technical Report 19722-2, Factory Mutual Research Corp., Norwood, Mass.

Alpert, R.L. (1975) "Turbulent Ceiling Jet Induced by Large-Scale Fire," Combustion Science and Technology 11, p.197

Beyler, C.L. (1986) "Fire Plumes and Ceiling Jets," Fire Safety J. 11, p.53

Handa, T., and Sugawa, O. (1982) "Turning Process of Growing Plume From an Unsteady Fire Source in an Enclosure," J. of Fire and Flammability 15, p.3

Heskestad, G., and Delichatsios, M.A. (1978) "The Initial Convective Flow in Fire," Proceedings of the 17th Symposium (International) on Combustion, the Combustion Institute, Pittsburgh, PA, p.1113

Heskestad, G., and Hamada, T. (1984) "Ceiling Flows of Strong Fire Plumes," FMRC Technical Report JI OK0E1.RU, Factory Mutual Research Corp., Norwood, Mass.

Kokkala, M.A. (1989) "Heat Transfer to and Ignition of Ceiling by an Impinging Diffusion Flame," Technical Report 586, Technical Research Center of Finland, Espoo, Finland

Kokkala, M.A. (1991) "Experimental Study of Heat Transfer to Ceiling From an Impinging Diffusion Flame," in Fire Safety Science - Proceedings of the Third Int'l Symposium (Eds., G. Cox and B. Langford), Elsevier Applied Science, N.Y., p. 261

Kung, H-C., Spaulding, R.D., and Stavrianidis, P. (1991) "Fire-Induced Flow Under a Sloped Ceiling," in Fire Safety Science - Proceedings of the Third Int'l Symposium (Eds., G. Cox and B. Langford), Elsevier Applied Science, N.Y., p. 271 
Motevalli, V., and Marks, C.H. (1991) "Characterizing the Unconfined Ceiling Jet Under Steady-State Conditions: A Reassessment," in Fire Safety Science - Proceedings of the Third Int'l Symposium (Eds., G. Cox and B. Langford), Elsevier Applied Science, N.Y., p.301

Veldman, C.C., Kubota, T., and Zukoski, E.E. (1975) "Experimental Investigation of the Heat Transfer From a Buoyant Gas Plume to a Horizontal Ceiling. Part 1, Unobstructed Ceiling," NBS-GCR-77-97, National Institute of Standards and Technology (U.S.), Gaithersburg, MD

You, H.Z., and Faeth, G.M. (1978) "An Investigation of Fire Impingement on a Horizontal Ceiling," NBS-GCR-79-188, National Bureau of Standards (U.S.), Gaithersburg, MD

You, H.Z., and Faeth, G.M. (1980) "An Investigation of Fire Impingement on a Horizontal Ceiling," NBS-GCR-80-251; National Institute of Standards and Technology (U.S.),

Gaithersburg, MD

You, H.Z., and Faeth, G.M. (1979) "Ceiling Heat Transfer During Fire Plume and Fire Impingement," Fire and Materials 3, No.3, p.140

You, H.Z., and Faeth, G.M. (1981) "An Investigation of Fire Impingement on a Horizontal Ceiling," NBS-GCR-81-304, National Institute of Standards and Technology (U.S.), Gaithersburg, MD

You, H.Z. (1984) "An Investigation of Fire-Plume Impingement on a Horizontal Ceiling. Part 1 -- Plume Region," Fire and Materials 8, p.28

You, H.Z. (1985) "An Investigation of Fire-Plume Impingement on a Horizontal Ceiling. Part 2 -- Impingement and Ceiling-Jet Regions," Fire and Materials 9, No.1, p.46

\section{Corner Fires Without Ceilings:}

Saito, K. (1993) Grant progress report; to be published.

\section{Corner Fires With Ceilings:}

Anonymous; 1982 Annual Book of ASTM Standards, Part 18, Am. Soc. for Testing and Materials, Philadelphia, PA

Cleary, T.G., and Quintiere, J.G. (1991) "A framework for utilizing fire property tests," in Fire Safety Science, Proceedings of the Third Int'l Symposium (Eds., G. Cox and B. Langford), Elsevier Applied Science, N.Y., p.64

Gross, D. (1988) "Measurements of Flame Lengths Under Ceilings," NISTIR 88-3835, National Institute of Standards and Technology (U.S.), Gaithersburg, MD, and 
Gross, D. (1989) "Measurement of Flame Lengths Under Ceilings," Fire Safety Journal 15, p.31

Karlsson, B., and Magnusson, S.E. (1990) "Room Fires and Combustible Linings," Chap. 33 in Fire and Polymers -- Hazards Identification and Prevention (Editor, G.L. Nelson); Symposium Series 425, American Chemical Society, Washington, DC

Karlsson, B., and Magnusson, S.E. (1991) "Combustible Wall Lining Materials: Numerical Simulation of Room Fire Growth and the Outline of a Reliability-Based Classification Procedure," in Fire Safety Science, Proceedings of the Third Int'1 Symposium (Eds., G. Cox and B. Langford), Elsevier Applied Science, N.Y., p.667

Karlsson, B. (1992) "A Mathematical Model for Calculating Heat Release in the Room Corner Test, Lund University, Dep't of Fire Safety Engineering, Report ISSN 1102-8246, Lund, Sweden

Nuh, S.M., and Williamson, R.B. (1973) "Fire Tests of Douglas-Fir Plywood Materials in an Open Corner Test, " Report CE-298-5, Dep't of Chemical Engineering, University of California, Berkeley, CA

Saito, K. (1993) Grant progress report; to be published.

Thomas, P.H. (1991) "Fire, Flames, and Dimensional Analysis," in Fire Safety Science Proceedings of the Third Int'l Symposium (Eds., G. Cox and B. Langford), Elsevier Applied Science, N.Y., p. 3.

Fires on Flat Walls / Corridor Fires:

Alpert, R.L., Mathews, M.K., and Modak, A.T. (1981) "Modeling of Ceiling Fire Spread and Thermal Radiation," FMRC Technical Report J.I. OEON8.BU, Factory Mutual Research Corp., Norwood, Mass.

Atallah, S. (1966) "Fires in a model corridor with a simulated combustible ceiling. Part I -radiation, temperature, and emissivity measurements," Joint Fire Research Organization Fire Research Note No. 620, Fire Research Station, Borehamwood, England.

Babrauskas, V. (1980) "Flame Lengths Under Ceilings," Fire and Materials 4, No.3, p.119

Mao, C-P., Fernandez-Pello, C.P., and Humphrey, J.A.C. (1984) "An Investigation of Steady Wall-Ceiling and Partial Enclosure Fires," J. of Heat Transfer 106, p. 221

Thomas, P.H., "Factors Affecting Ignition of Combustible Materials and Their Behavior in Fire," International Symposium on Fire Safety of Combustible Materials, University of Edinburgh, Centre for Industrial Consultancy and Liason, October, pp. 84-89. 


\section{FIGURE CAPTIONS}

Fig. 1. Side view of channel.

Fig. 2. End view of channel.

Fig. 3. Experimental arrangement, NIST reduced-scale experiments (dimensions in $\mathrm{mm}$ ).

Fig. 4. Mass-loss rates, NIST reduced-scale experiments.

Fig. 5. Smoothed mass-loss rates, NIST reduced-scale experiments.

Fig. 6. Radiative heat flux to radiometer mounted flush to upper back wall near PMMA specimen, NIST reduced-scale experiments.

Fig. 7. Radiative heat flux to radiometer mounted flush to lower back wall near PMMA specimen, NIST reduced-scale experiments.

Fig. 8. Total heat flux to Gardon heat-flux gauge mounted flush to floor at center of floor, NIST reduced-scale experiments.

Fig. 9. Calculated effect of radiation enhancement, due to ceiling/layer, on mass-loss rate of PMMA wall specimen compared with experiment, NIST reduced-scale experiments.

Fig. 10. Temperature profiles on a fire-heated Marinite vertical corner wall. A: with a Marinite ceiling; B: with no ceiling.

Fig. 11. Total heat flux distribution on a fire-heated Marinite corner wall. A: with a Marinite ceiling; B: with no ceiling.

Fig. 12. Rate of heat release from burning PMMA slabs, obtained by running SPREAD for 0.61-m wide, 2.44-m high slabs. NC: burned in the open. C: burned in an ASTM room. The arrows indicate the moment at which the pyrolysis front was calculated to reach the top of the slab, for the two cases. 


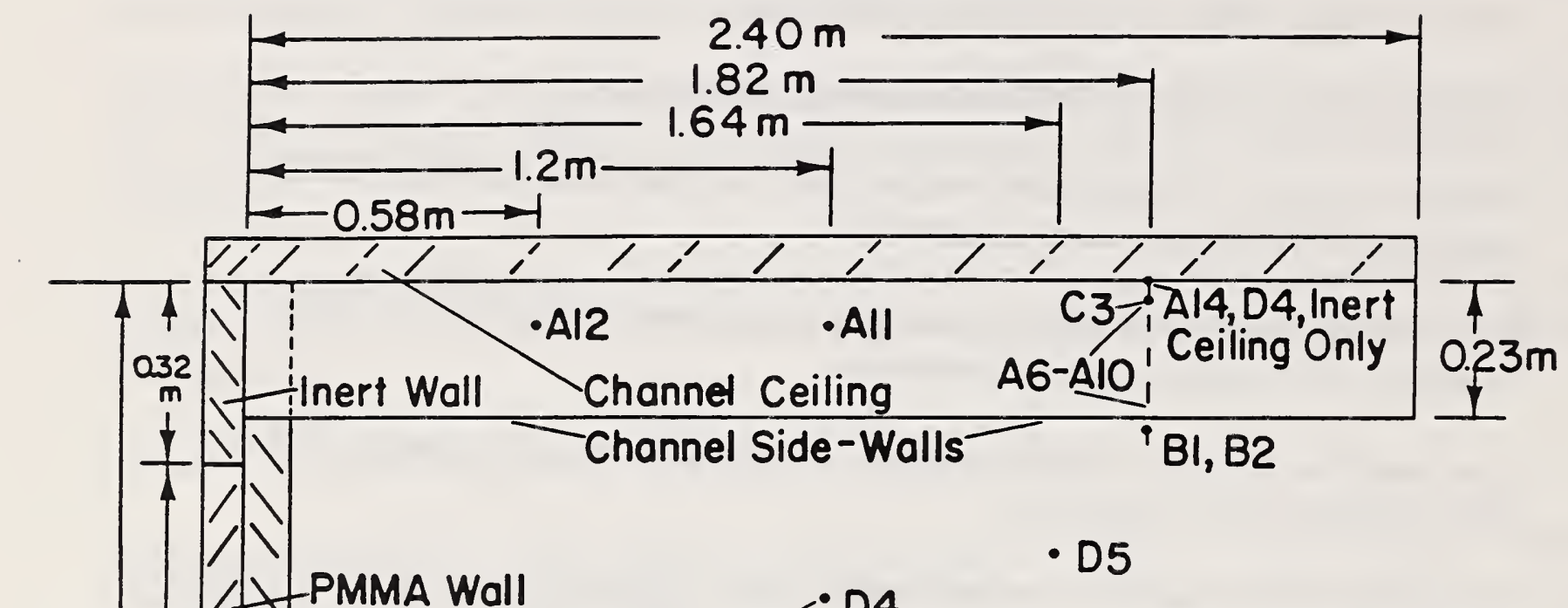

$1.22 \mathrm{~m}$
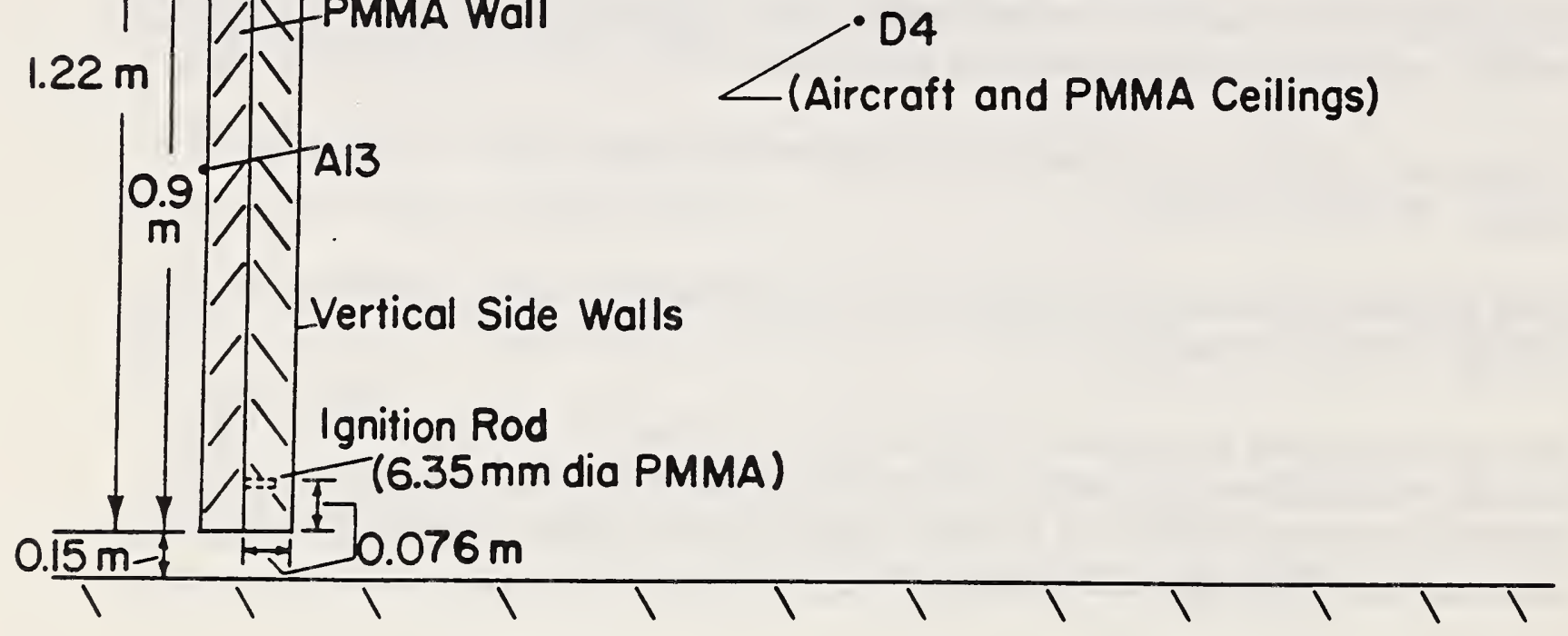

Side View of Channel

FIGURE I SIDE VIET: OF CHANNEL 
Ceiling

Configuration

for Test $7-9-80$

$460 \mathrm{~mm} \longrightarrow$

$\leftarrow 305 \mathrm{~mm} \rightarrow$

$50.8 \mathrm{~mm}$

Channel Ceiling

$E===\frac{1}{5} 125 \mathrm{~mm}$

Steel

Framework

Ceramic

Board

Side Walls

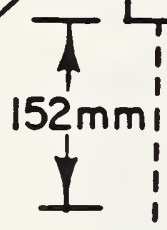

Ignition Rod

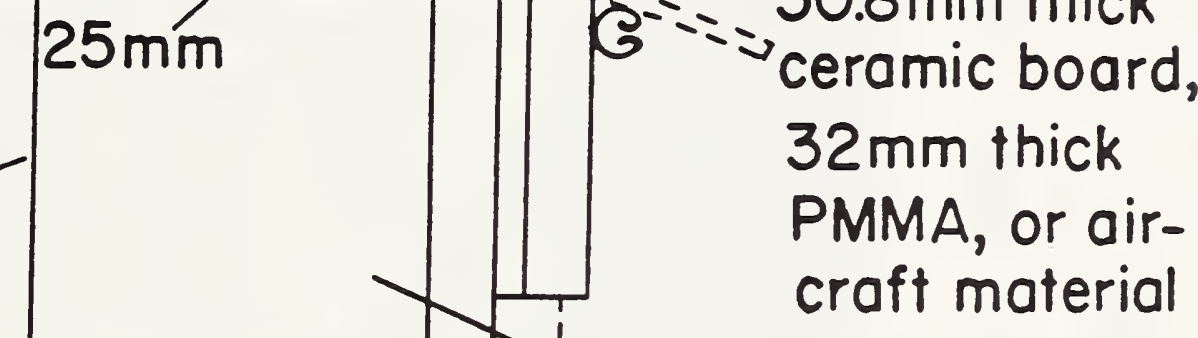

End View of Channel

FIGURE 2 END VIEK OF CHANNEL 


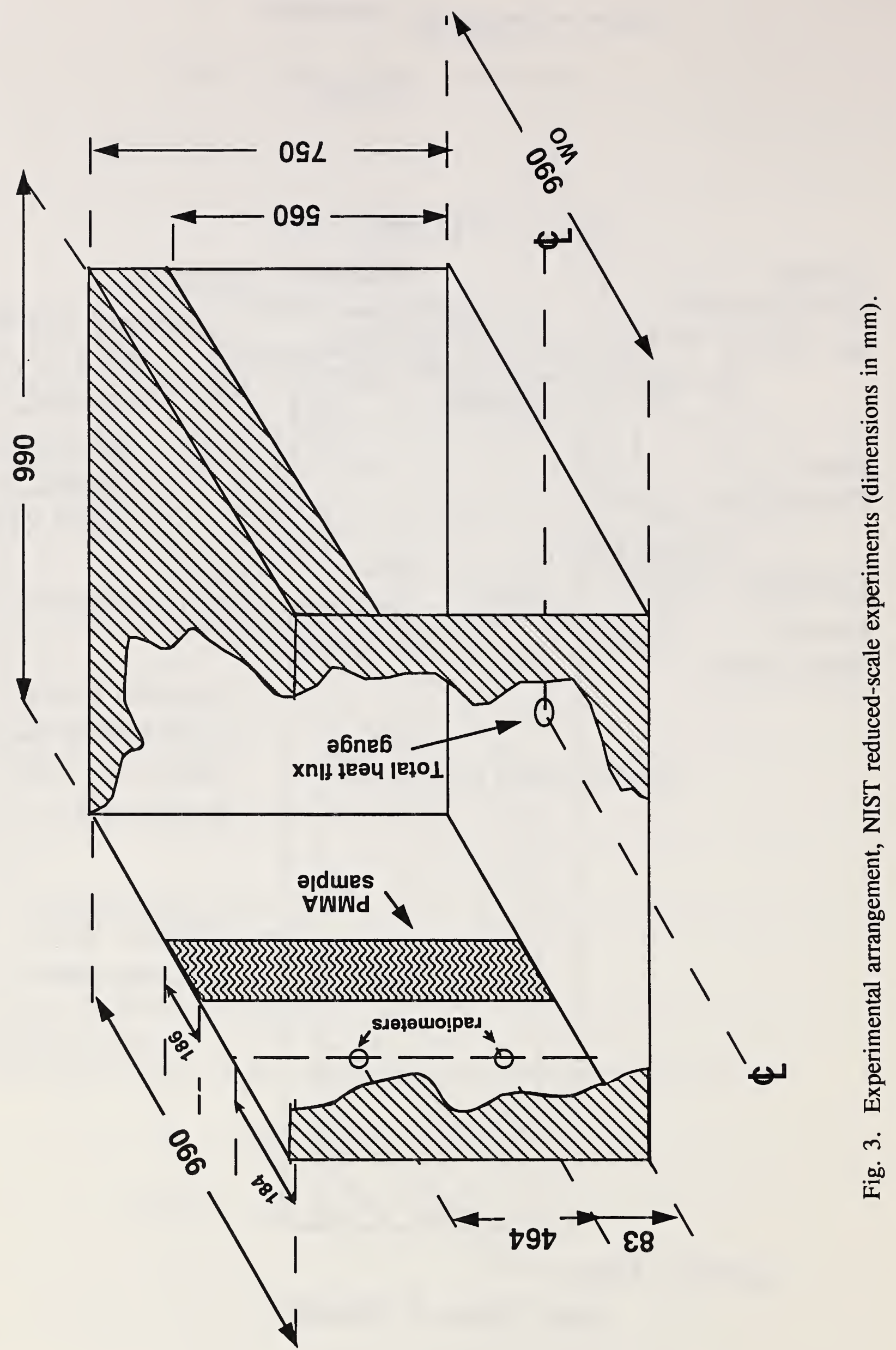




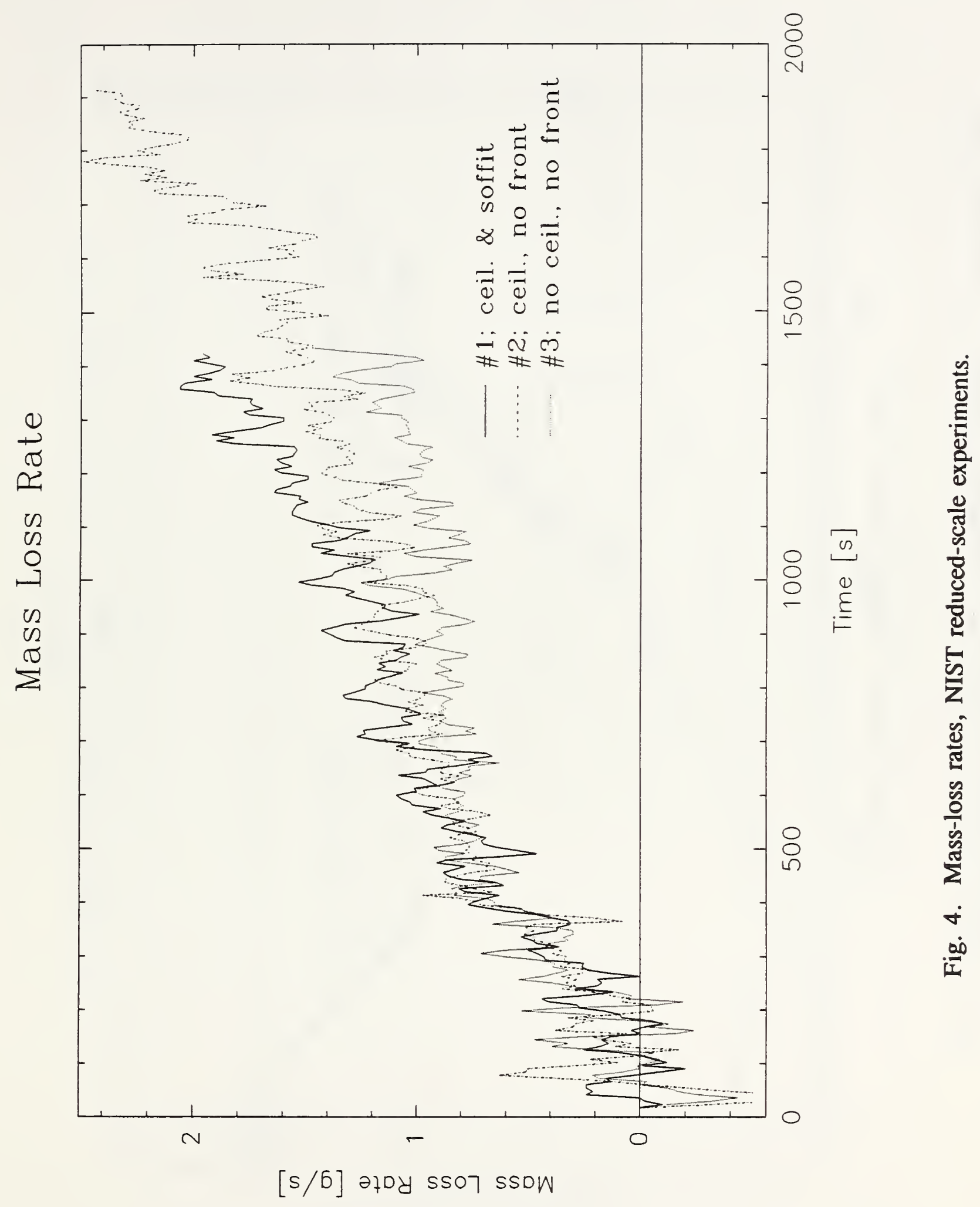




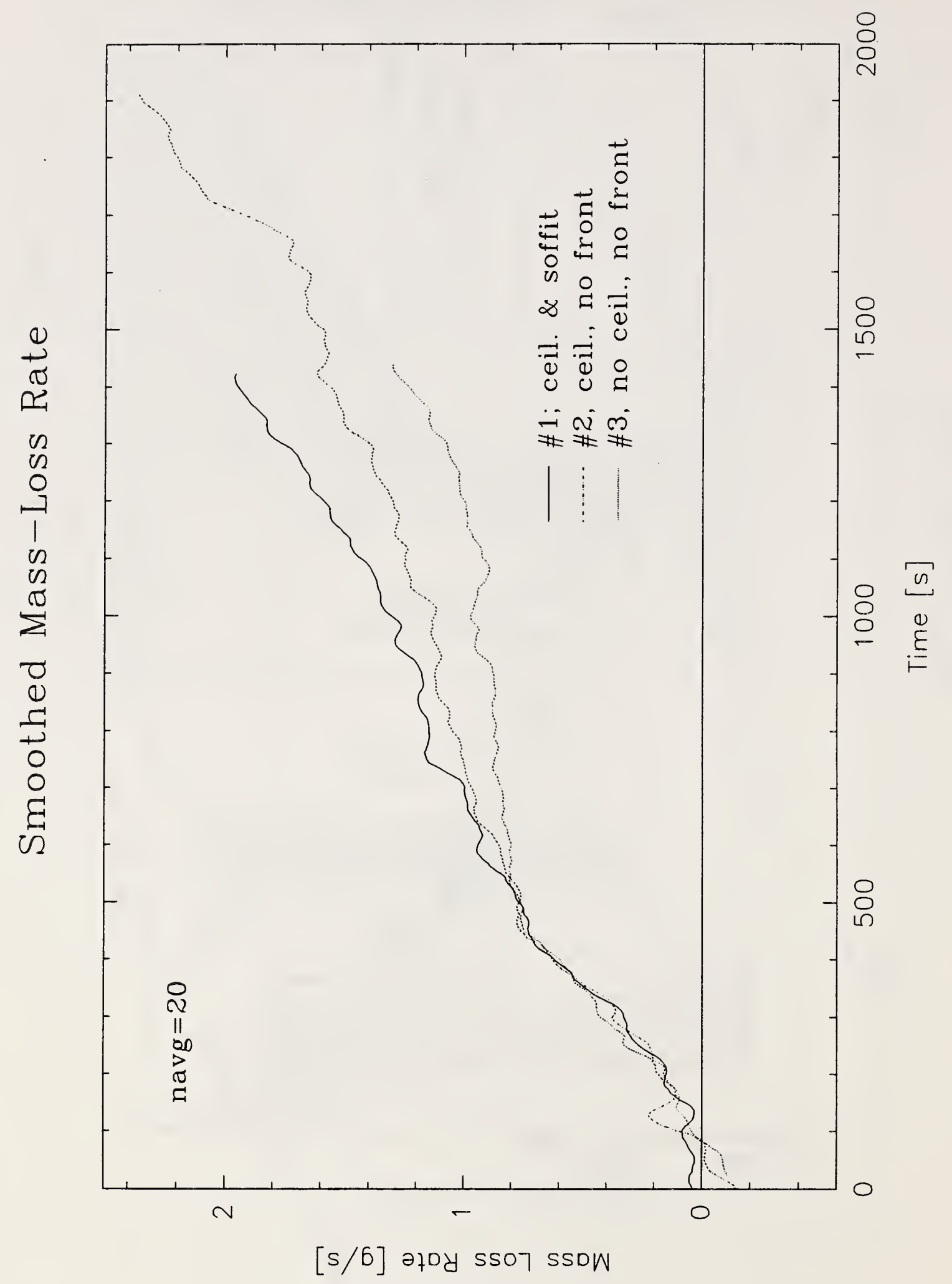

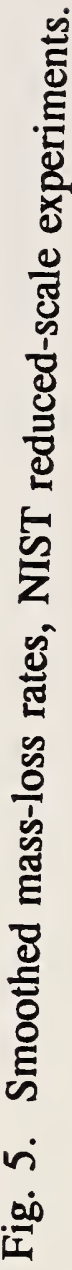




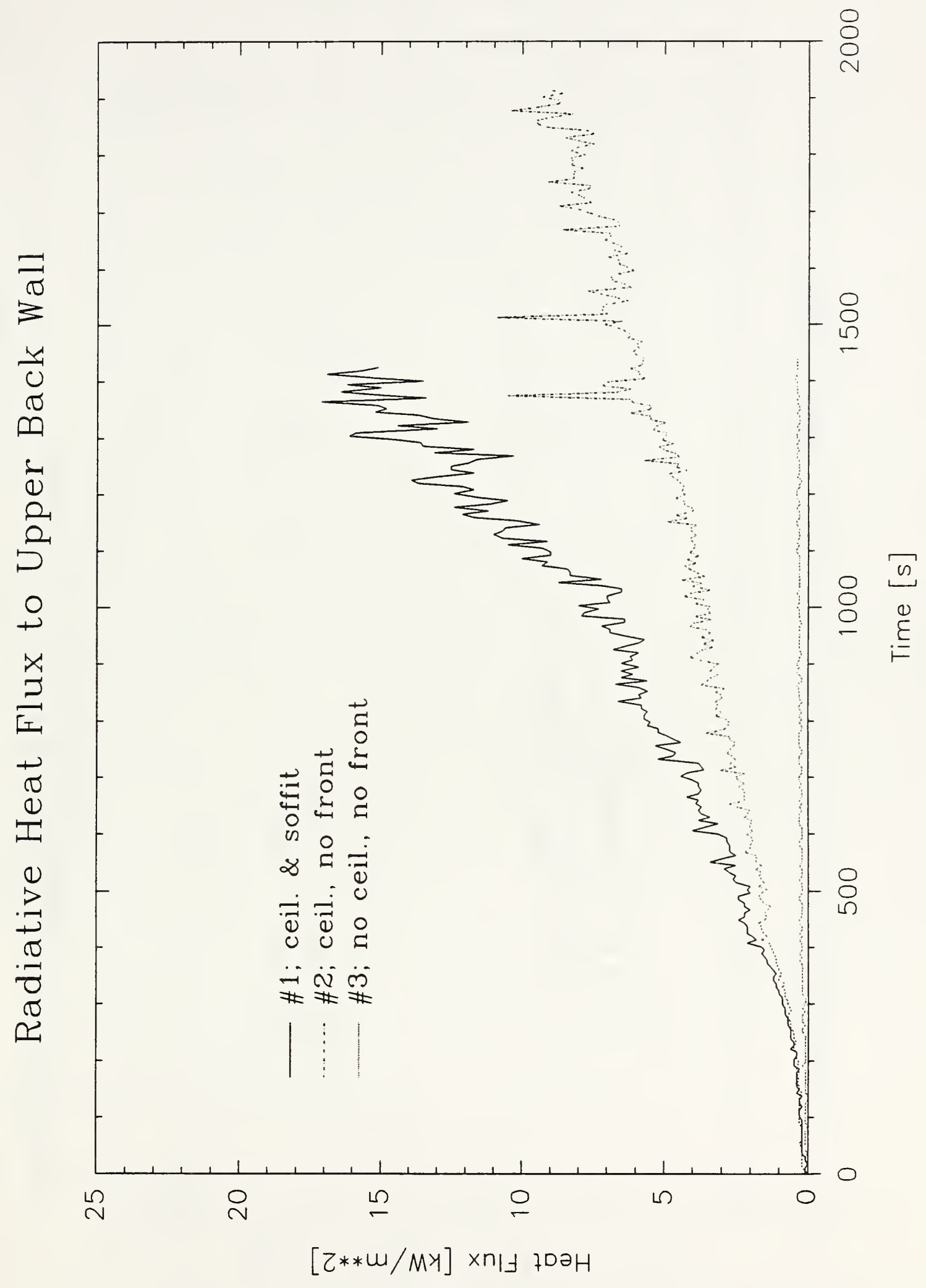

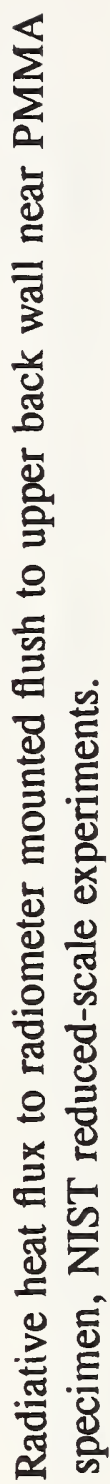

$0^{\circ}$

$\frac{\infty}{10}$ 


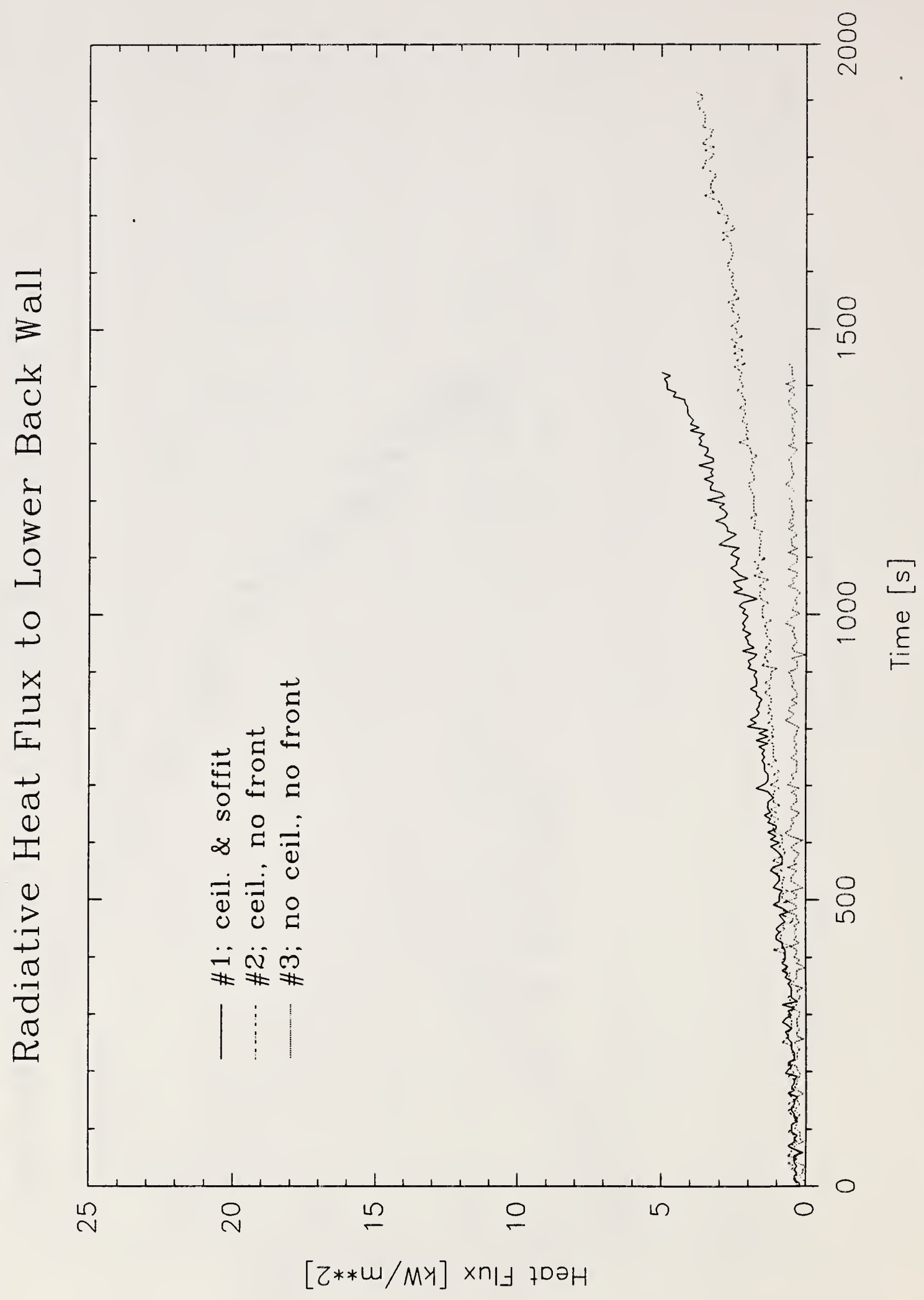

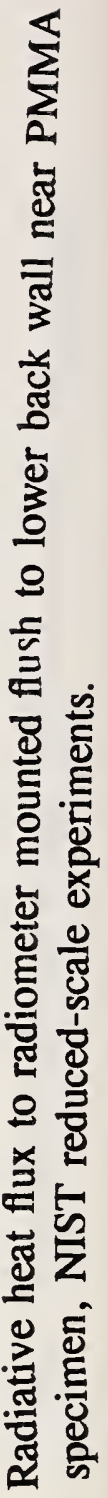
$r$ 量 


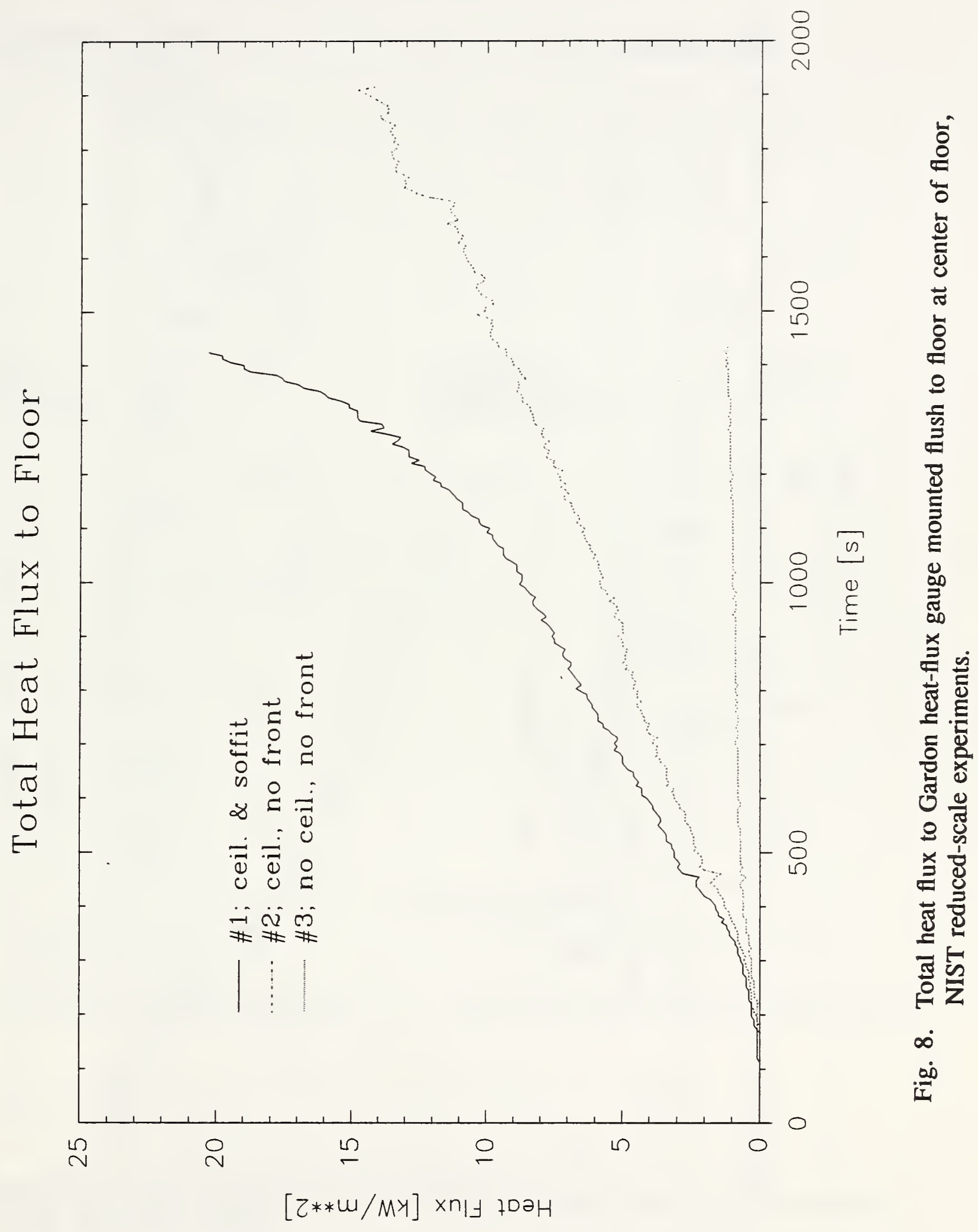




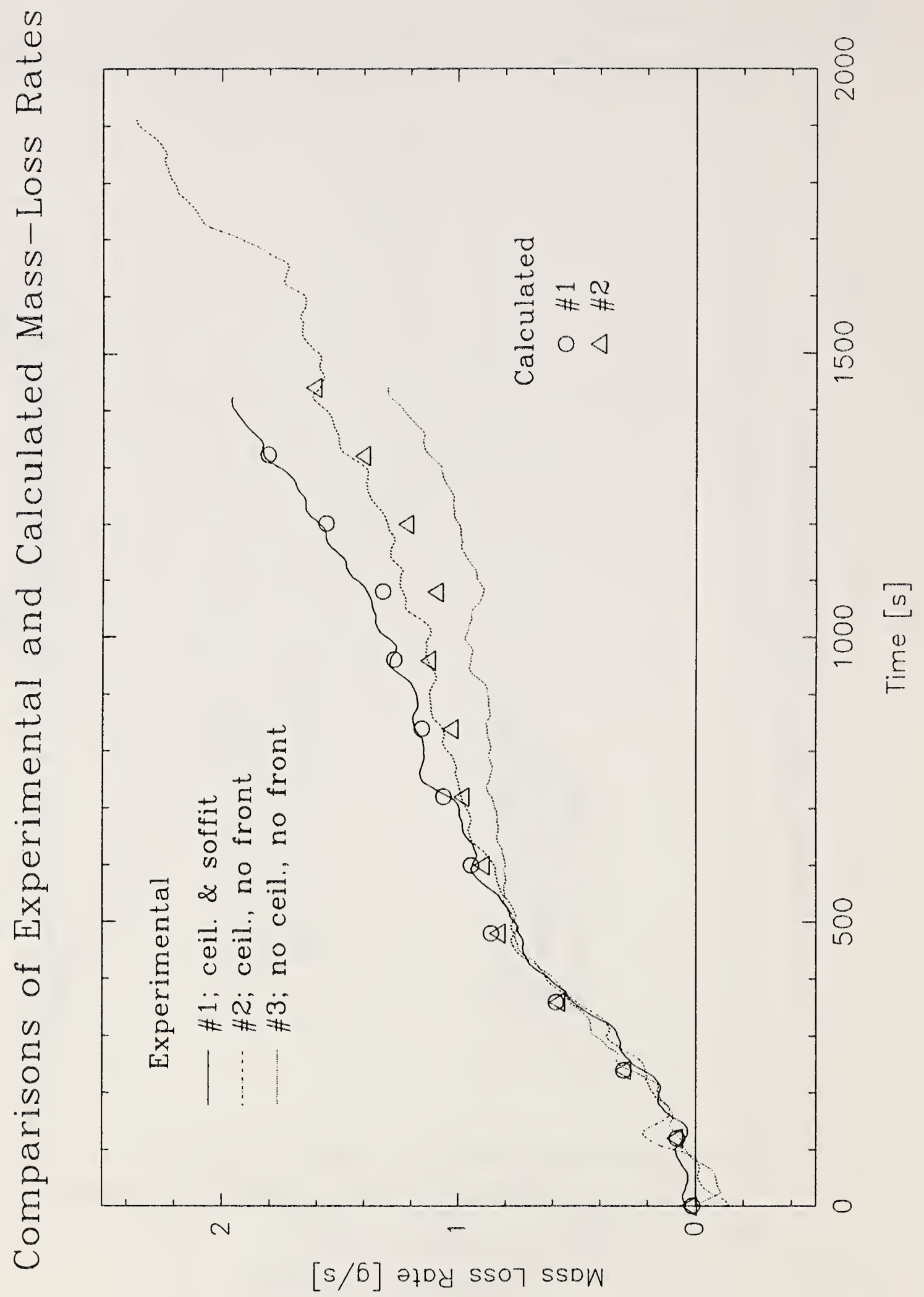

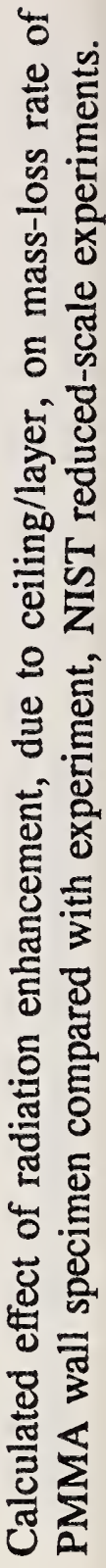

a

这 
BURNER HEAT RELEASE RATE: $18 \mathrm{~kW}$

BURNER STAND-OFF DISTANCE: $5 \mathrm{~cm}$

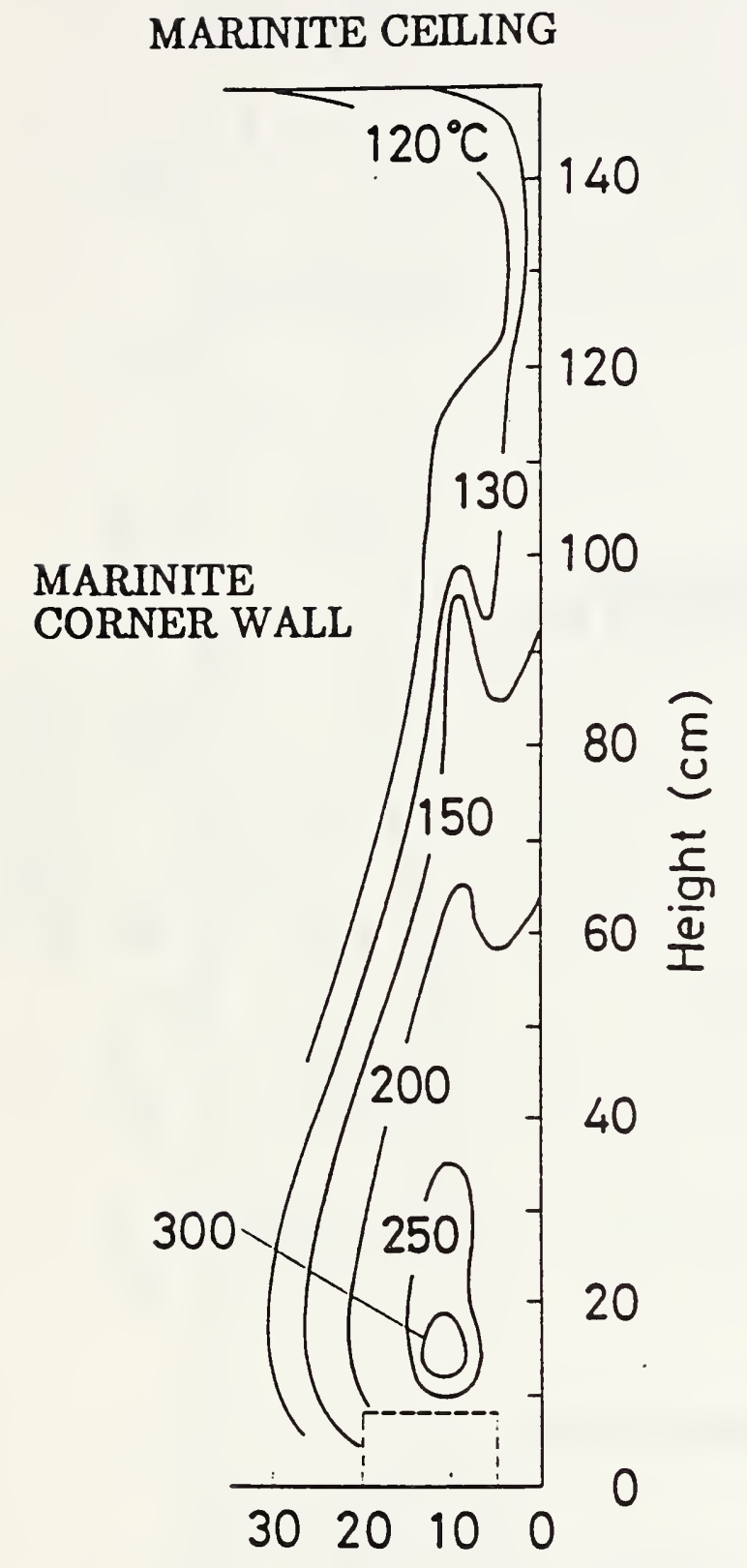

DISTANCE FROM THE CORNER (cm)

(A)

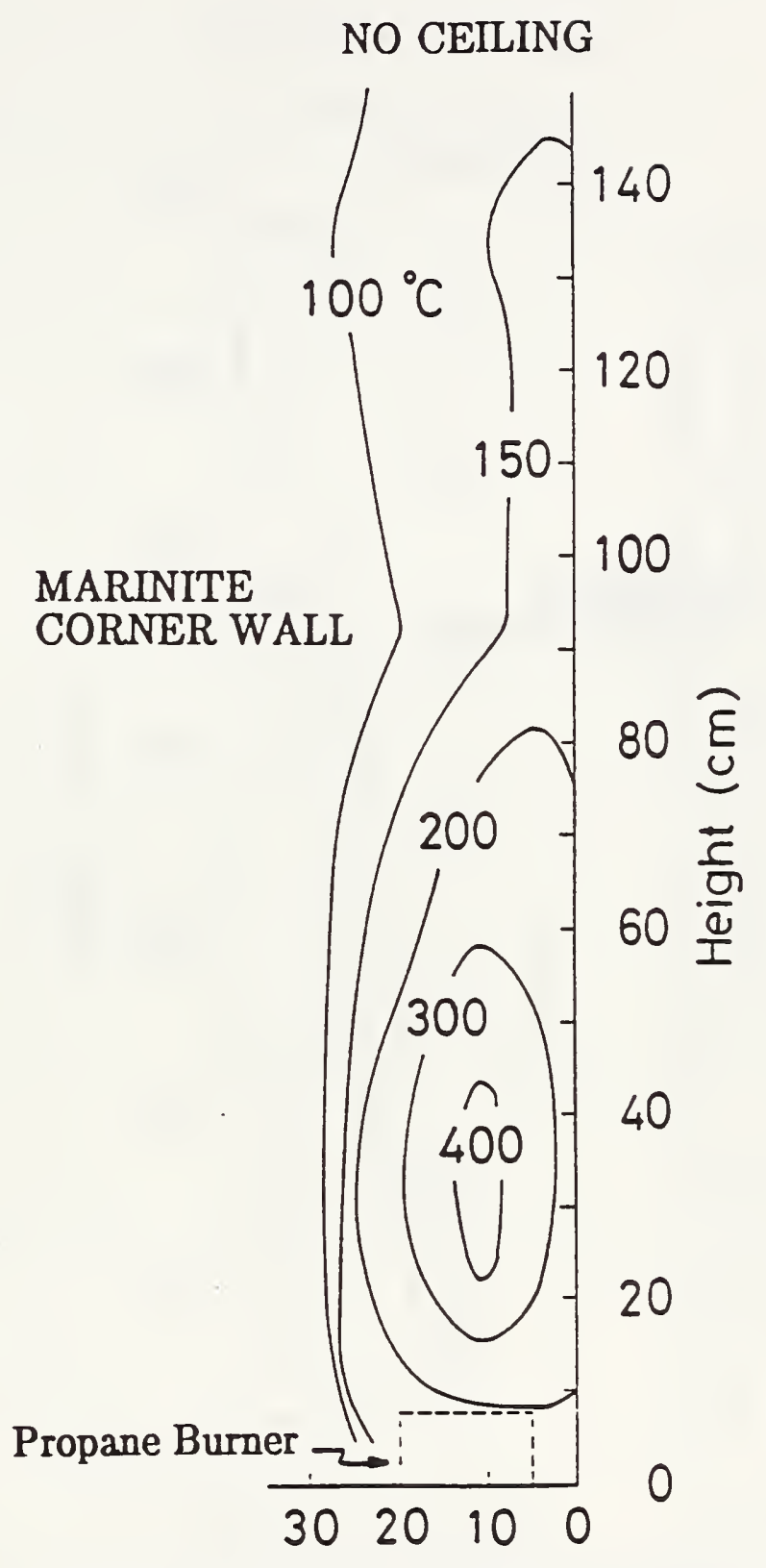

DISTANCE FROM THE CORNER (cm)

Fig. 10. Temperature profiles on a fire-heated Marinite vertical corner wall. A: with a Marinite ceiling; B: with no ceiling. 
BURNER HEAT RELEASE RATE: 18kW

BURNER STAND-OFF DISTANCE: $5 \mathrm{~cm}$

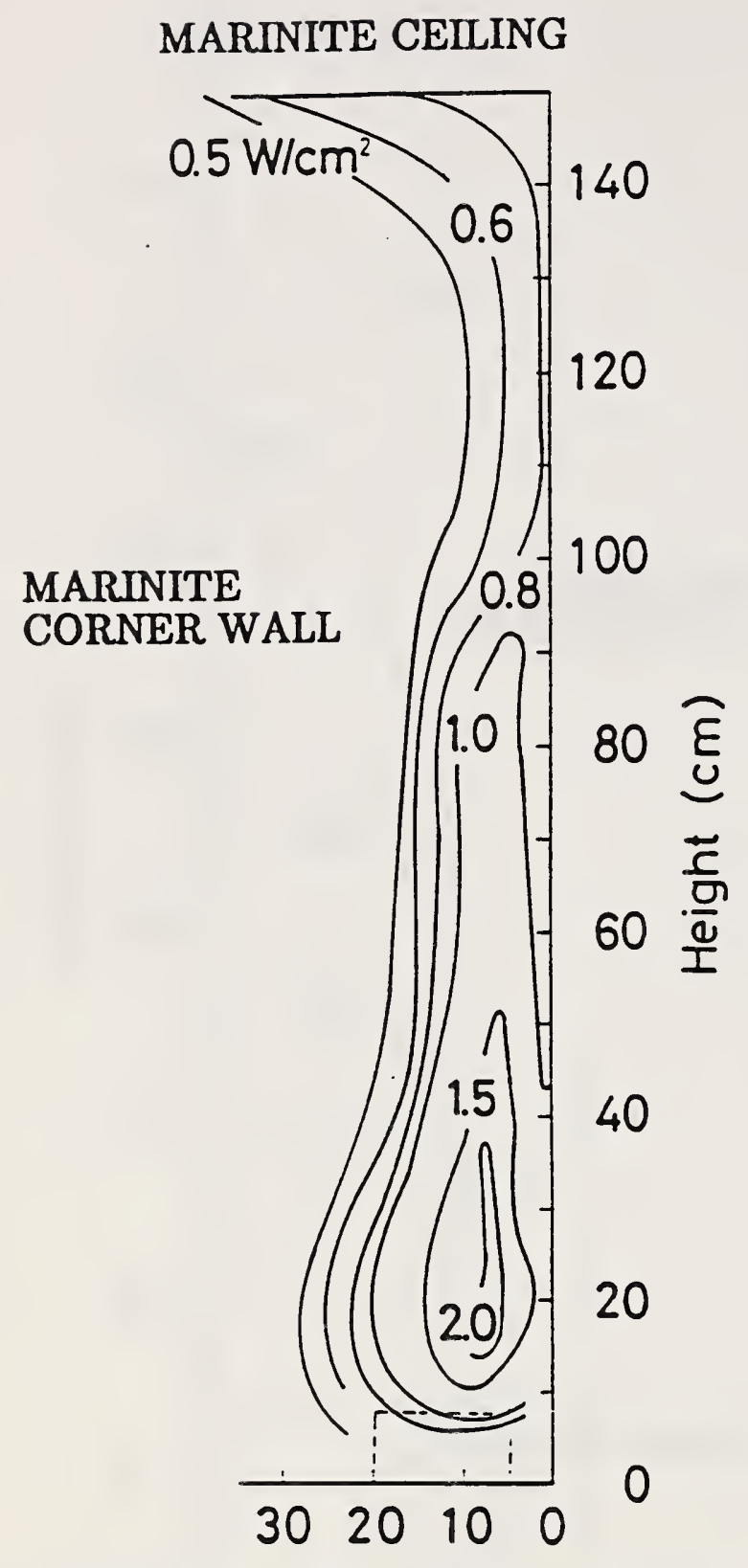

DISTANCE FROM THE CORNER (cm)

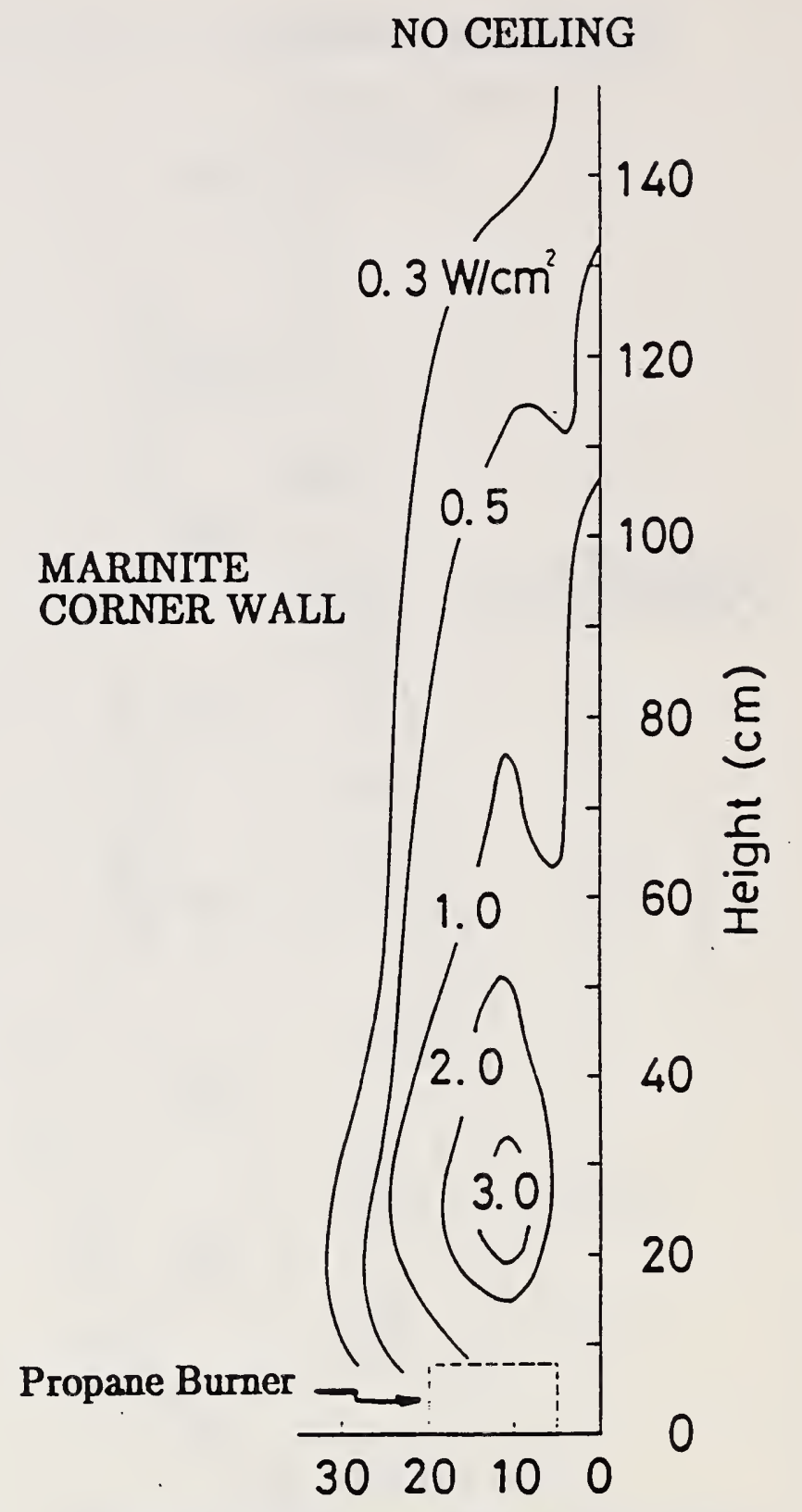

DISTANCE FROM THE CORNER (cm)

Fig. 11. Total heat flux distribution on a fire-heated Marinite corner wall. A: with a Marinite ceiling; B: with no ceiling. 


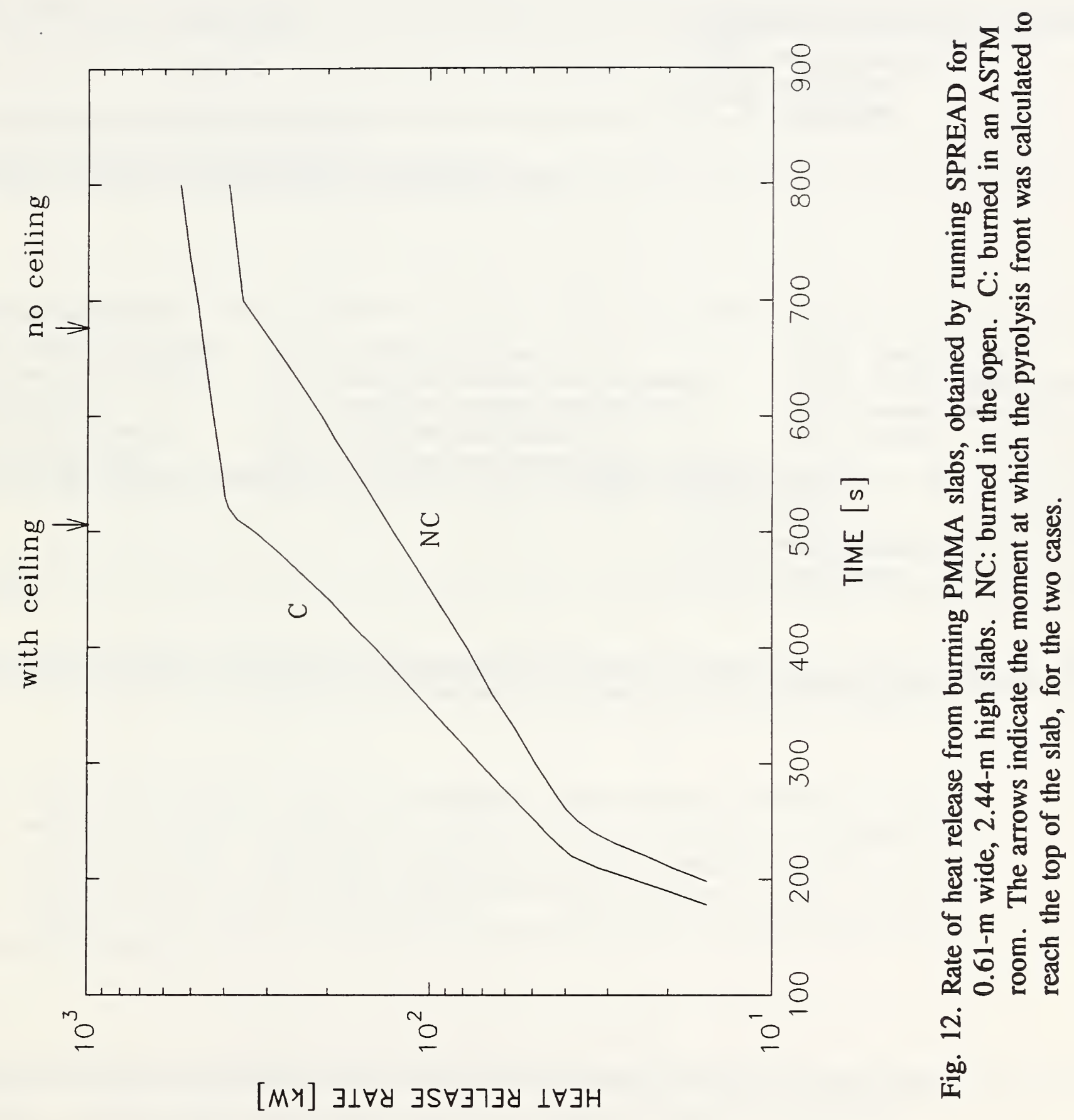





\section{NIST-114 \\ (REV. 9-92) \\ ADMAN 4.09 \\ U.S. DEPARTMENT OF COMMERCE \\ NATIONAL INSTITUTE OF STANDARDS AND TECHNOLOGY}

\section{MANUSCRIPT REVIEW AND APPROVAL}

(ERB USE ONLY

\begin{tabular}{|l|l}
\hline ERB CONTROL NUMBER & DMSION
\end{tabular}

PUBUCATION REPOAT NUMBER

NISTIR 5380

PUBLCATION DATE

November 1994

THE SECRETARY, APPROPRIATE EDITORIAL REVIEW BOARD.

TITLE AND SUBTITLE (CITE IN FULU)

Comparison of Wa11-Fire Behavior With and Without a Ceiling

\begin{tabular}{|l|l|}
\hline CONTRACT OR GRANT NUMBER & TYPE OF REPORT AND/OR PERIOD COVERED \\
\hline
\end{tabular}

AUTHOR(S) (LAST MAME, FIRST INITIAL, SECOND INITIAL)

H.E. Mitler and K.D. Steckler

PERFORMING ORQANIZATION (CMECK $(X)$ ONE BOX)

$\mathrm{X}$ NIST/GANTHERSBURG

NIST/BOULDER

JILA/BOULER

LABORATORY AND DIVISION NAMES (FIRST NIST AUTHOR ONLY)

Building Fire Research Laboratory/Fire Modeling SPONSORING ORGANIZATION NAME AND COMPLETE ADDRESS (STREET, CITY, STATE, ZIP)

SUPPLEMENTARY NOTES

JOURHAL OF RESEARCH (NIST JRES)

J. PHYS. \& CHEM. REF. DATA (JPCRD)

MANDBOOK (NIST HB)

SPECIAL PUBLCATION (NIST SP)

TECHNICAL NOTE (NIST TM)

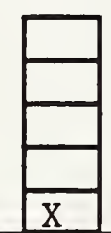

MONOGRAPH (NIST MN)

MATL STD. REF. DATA SERIES (MIST NSRDS)

FEDERAL INF. PROCESS. STOS. (NIST FIPS)

UST OF PUBUCATIONS (NIST LP)

NIST INTERAGENCY/INTERNAL REPORT (NISTIR)

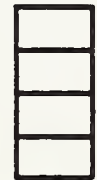

LETTER CIRCULAR

BUILDINO SCIENCE SERIES

PRODUCT STAMDARDS

OTHER

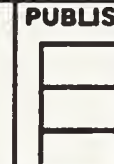

PAPER

DISKETTE (SPECIF)

OTHER (SPECIPY)

This paper demonstrates that the effects of the ceiling on the progress of a wall fire are quite significant, and that a project to quantify and model the effects of a ceiling on the progress of a wall fire is indeed justified. Experimental results from the open literature are used for this purpose, as well as previously-unpublished experimental results obtained at NIST. The wallfire model SPREAD and the room-fire model FIRST are used seriatim to show that part of this effect can be calculated now.

KEY WORDS (MAXIMUM 9 KEY WORDS; 28 CHARACTERS AND SPACES EACH; ALPHABETICAL ORDER; CAPITALZE ONLY PROPER NAMES)

burning rates; ceiling fires; ceiling jets; fire research; fires on ceilings; radiation feedback; spread rates; wall fires

\section{AVAILABIUTY}

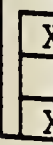
UNUMITED FOR OFFICIAL DISTRIBUTION. DO NOT RELEASE TO NTIS. ORDER FROM SUPERINTENDENT OF DOCUMENTS, U.S. GPO, WASHINGTON, D.C. 20402 ORDER FROM NTIS, SPRINGFIELD, VA 22161
MOTE TO AUTHOR(S) IF YOU DO MOT WISH THIS MANUSCRIPT ANNOUNCED BEFORE PUBUCATION, PLEASE CHECK HERE. 


